\title{
Self-assembly of Metallamacrocycles Employing a New Benzil-based Organo- metallic Bisplatinum(II) Acceptor
}

\author{
Bijan Roy, Sankarasekaran Shanmugaraju, Rupak Saha, and Partha Sarathi Mukherjee*
}

\begin{abstract}
A benzil-based semi-rigid dinuclear organometallic acceptor 4,4'-bis[trans-Pt $\left(\mathrm{PEt}_{3}\right)_{2}\left(\mathrm{NO}_{3}\right)$ (ethynyl)]benzil (bisPt-NO $_{3}$ containing a Pt-ethynyl functionality was synthesized in good yield and characterized by multinuclear NMR $\left({ }^{1} \mathrm{H},{ }^{31} \mathrm{P}\right.$, and $\left.{ }^{13} \mathrm{C}\right)$, electrospray ionization mass spectrometry (ESI-MS), and single-crystal X-ray diffraction analysis of the iodide analogue bisPt-I. The stoichiometric (1:1) combination of the acceptor bisPt- $\mathrm{NO}_{3}$ separately with four different ditopic donors $\left(\mathbf{L}_{1}-\mathbf{L}_{4} ; \mathbf{L}_{1}=9\right.$-ethyl-3,6-di $\left(1 H\right.$-imidazol-1-yl)- $9 H$-carbazole, $\mathbf{L}_{2}=1,4$-bis $((1 H$-imidazol-1-yl)methyl)benzene, $\mathbf{L}_{3}=1,3$-bis $\left(\left(1 H\right.\right.$-imidazol-1-yl)methyl)benzene and $\mathbf{L}_{4}=9,10$-bis $((1 H$-imidazol-1-yl) methyl)anthracene) yielded four [2 +2 ] self-assembled metallacycles $\mathbf{M}_{1}-\mathbf{M}_{\mathbf{4}}$ in quantitative yields, respectively. All these newly synthesized assemblies were characterized by various spectroscopic techniques (NMR, IR, ESIMS) and their sizes/shapes were predicted through geometry optimization employing the PM6 semi-empirical method. The benzil moiety was introduced in the backbone of the acceptor bisPt-NO $\mathrm{N}_{3}$ due to the interesting structural feature of long carbonyl $\mathrm{C}-\mathrm{C}$ bond $(\sim 1.54 \AA)$, which enabled us to probe the role of conformational flexibility on size and shapes of the resulting coordination ensembles.
\end{abstract}

Keywords: Flexible bisplatinum acceptor $\cdot$ Metallamacrocycle $\cdot$ Self-assembly

\section{Introduction}

Chemists have long desired to develop molecular ensembles with diverse shapes, sizes, and functionalities in order to mimic complex biological systems and also to explore such systems for practical applications. [1] The rapid development of synthetic methodologies has made it possible to synthesize various intricate macrocycles/ cages, which have found significant importance for the applications in drug delivery, sensing, catalysis and host-guest chemistry. ${ }^{[2]}$ However, the conventional covalent (C-C bond formation) synthesis of such functional smart materials often involves multi-step reactions and hence found to be laborious, time consuming and results in low yield of the targeted products. ${ }^{[3]}$ Thus, it remains a constant challenge for the scientific community to introduce alternative synthetic methodologies targeting minimum synthetic difficulties to achieve desired products with maximum possible yields. In light of this, coordination-driven self-assembly has become one of the powerful strategies for one-pot synthesis of desired molecular architectures in high yield. ${ }^{[4]}$ The stable coordination geometry of square planar $\mathrm{Pd}(\mathrm{II})$ and $\mathrm{Pt}(\mathrm{II})$ metal ions and their dynamic metal-ligand coordination bond formation with N/Odonors gives them the potential to achieve thermodynamically stable single products over several kinetically driven possibilities, as nicely described in the 'Molecular library' by Stang et al. ${ }^{[5]}$ But the rapid development of the field demands the design and synthesis of more sophisticated and unprecedented molecular architectures beyond the existing molecular library. For this purpose, the use of flexible building blocks is a popular approach to achieve unusual structural features. Though a large number of rigid/semi-rigid donors has been extensively used for this pur- pose, ${ }^{[6]}$ the use of flexible metal-acceptors is very rare. Our group has been actively involved in this field to develop efficient self-assembled 2D/3D architecture for the sensing of nitroaromatic explosives, small molecules and various anions. ${ }^{[7]}$ The present study introduces a novel benzil-based semi-rigid bisplatinum(II) acceptor bisPt$\mathrm{NO}_{3}$ which was utilized to obtain four new $[2+2]$ metallamacrocycles $\left(\mathbf{M}_{1}-\mathbf{M}_{4}\right)$ in almost quantitative yields by heating with equimolar amounts of the imidazole based ditopic donors $\left(\mathbf{L}_{\mathbf{1}}-\mathbf{L}_{\mathbf{4}}\right)$ of different size and rigidity in 1:1 chloroform/acetone solvent mixture (Scheme 1). All the macrocycles were fully characterized by multinuclear NMR and ESI-MS spectrometry. Semiempirical PM6 geometry optimization was carried out for all the four macrocycles to illuminate their structures.

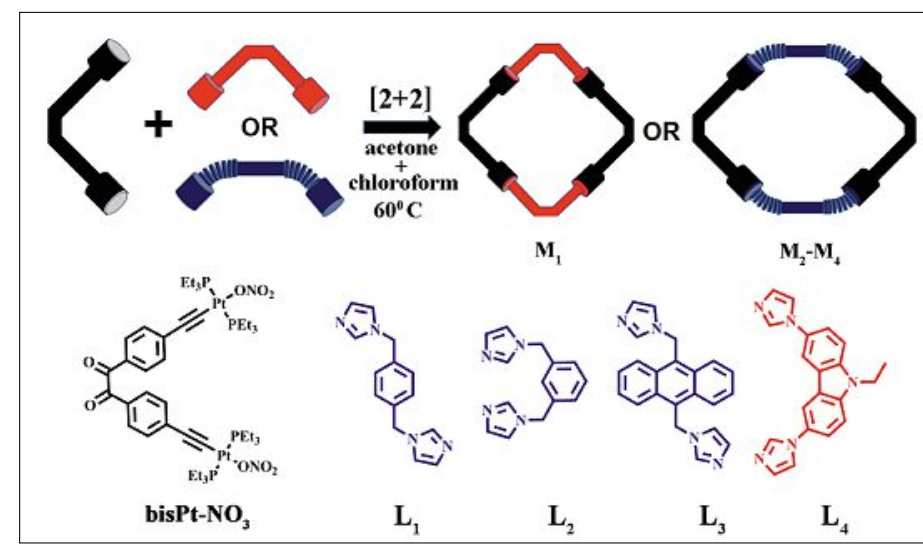

Scheme 1. [2 + 2] Self-assembly of metallamacrocycles $\left(\mathbf{M}_{1}-\mathbf{M}_{4}\right)$ using a new benzil-based organometallic bisplatinum acceptor bisPt-NO in combination with four different ditopic imidazole donors $\left(\mathbf{L}_{1}-\mathbf{L}_{4}\right)$. 


\section{Experimental Section}

\section{Materials and Methods}

The bisplatinum intermediate bisPt-I was synthesized under dry nitrogen atmosphere using standard Schlenk techniques. All the solvents were dried and freshly distilled prior to the reactions. The starting materials 4,4'-dibromobenzil, imidazole, anthracene, carbazole, dibromo- $p$-xylene, dibromo- $m$-xylene and other reagents were purchased from various commercial sources and used without further purification. All four donors $\left(\mathbf{L}_{\mathbf{1}}-\mathbf{L}_{\mathbf{4}}\right)$ were synthesized by following literature procedures. ${ }^{[8]}$ NMR spectra were recorded in a Bruker $400 \mathrm{MHz}$ spectrometer and the chemical shifts are reported in ppm with respect to standard reference tetramethylsilane $\left(\mathrm{Me}_{4} \mathrm{Si}, \delta=0.00 \mathrm{ppm}\right)$ or the solvent peaks arising due to their incomplete deuteration $\left(\delta=7.26\right.$ for $\mathrm{CDCl}_{3}, \delta=1.94$ for $\mathrm{CD}_{3} \mathrm{CN}$ in case of ${ }^{1} \mathrm{H}$ NMR). ESI-MS spectra were recorded in an Agilent 6538 Ultra-High Definition (UHD) Accurate Mass Q-TOF spectrometer. IR experiments were done in a Bruker ALPHA FTIR spectrometer. A Perkin-Elmer Lambda $750 \mathrm{UV} / \mathrm{Vis}$ spectrophotometer was used for recording absorbance spectra, while the emission spectra was obtained using HORIBA Jovin Yvon Fluoromax-4 spectrometer. HPLC grade solvents were used for UV/Vis and fluorescence spectroscopic studies.

\section{Synthesis of 4,4'-Diethynylbenzil (1)}

An oven-dried $100 \mathrm{~mL}$ two-neck round bottom flask was charged with 4,4'-dibromobenzil $(2.0 \mathrm{~g}, 5.43 \mathrm{mmol})$, trans-[P$\left.\mathrm{dCl}_{2}\left(\mathrm{PPh}_{3}\right)_{2}\right](0.114 \mathrm{~g}, 0.16 \mathrm{mmol}), \mathrm{CuI}$ $(0.031 \mathrm{~g}, 0.16 \mathrm{mmol})$ and $70 \mathrm{~mL}$ of dry $\mathrm{NEt}_{3}$ under nitrogen atmosphere. Then trimethylsilylacetylene (1.9 mL, $13.7 \mathrm{mmol})$ was added to the mixture and it was refluxed at $85{ }^{\circ} \mathrm{C}$ for $36 \mathrm{~h}$. After completion of the reaction (as monitored by TLC), the solvent was evaporated completely and the product was purified by column chromatography in silica gel by eluting with chloroform-hexane (9:1) mixture to obtain 4,4'-trimethylsilylethynylbenzil as light yellow powder. Isolated yield $=78 \% .{ }^{1} \mathrm{H}$ NMR $\left(\mathrm{CDCl}_{3}, 400 \mathrm{MHz}\right): \delta=7.91(\mathrm{~d}, J$ $=8.81 \mathrm{~Hz}, 4 \mathrm{H}, \mathrm{Ar}-\mathrm{H}), 7.58(\mathrm{~d}, J=8.31$
$\mathrm{Hz}, 4 \mathrm{H}, \mathrm{Ar}-\mathrm{H}$ ), 0.26 (s, 18H, Me $\mathrm{Si}-\mathrm{H}$ ). ${ }^{13} \mathrm{C} \mathrm{NMR}\left(\mathrm{CDCl}_{3} 100 \mathrm{MHz}\right): \delta=193.44$, $132.84,132.57,130.37130 .13,104.18$, $100.30,0.23$.

A solution of 4,4'-trimethylsilylethynylbenzil (1.5 g, $3.72 \mathrm{mmol})$ in dichloromethane-methanol $(1: 1)$ mixture was stirred with potassium carbonate $(515 \mathrm{mg}$, $3.72 \mathrm{mmol}$ ) for $2 \mathrm{~h}$ at room temperature. The solvent was evaporated completely and the solid residue was filtered through silica gel matrix using 1:1 chloroform-hexane mixture to obtain pure desilylated 4,4'-diethynylbenzil (1) as a pale brown powder (86\%). Anal calcd for $\mathrm{C}_{18} \mathrm{H}_{10} \mathrm{O}_{2}: \mathrm{C}, 83.71$; $\mathrm{H}, 3.90$. Found: C, 83.42; H, 4. 08. ${ }^{1} \mathrm{H}$ NMR $\left(\mathrm{CDCl}_{3}, 400 \mathrm{MHz}\right): \delta=7.94(\mathrm{~d}, J=8.81$ $\mathrm{Hz}, 4 \mathrm{H}, \mathrm{Ar}-\mathrm{H}), 7.62$ (d, $J=8.78 \mathrm{~Hz}, 4 \mathrm{H}$, $\mathrm{Ar}-\mathrm{H}), 3.33$ (s, 2H, alkyne-H); ${ }^{13} \mathrm{C}$ NMR $\left(\mathrm{CDCl}_{3}, 100 \mathrm{MHz}\right): \delta=193.42,133.13$, $132.95,130.22,129.39,82.92,82.25$.

\section{Synthesis of bisPt-I}

A mixture of 4,4'-diethynylbenzil (1; $0.100 \mathrm{~g}, 0.38 \mathrm{mmol})$, trans- $\left[\mathrm{PtI}_{2}\left(\mathrm{PEt}_{3}\right)_{2}\right]$ $(0.796 \mathrm{~g}, 1.16 \mathrm{mmol})$ and $\mathrm{CuI}(0.0074 \mathrm{~g}$, $0.038 \mathrm{mmol}$ ) was placed in an oven-dried Schlenk flask and $15 \mathrm{~mL}$ dry toluene-diethylamine (2:1) solvent mixture was added to it. The solution was stirred for $48 \mathrm{~h}$ at room temperature under nitrogen atmosphere until TLC confirmed the completion of the reaction. The solvent was evaporated completely and the crude product was purified by silica-gel column chromatography using 1:9 ethyl acetate-hexane mixture as eluent to get iodide analogue bisPt-I as yellow solid in 64\% yield (Scheme 2). Anal calcd for $\mathrm{C}_{42} \mathrm{H}_{68} \mathrm{I}_{2} \mathrm{O}_{2} \mathrm{P}_{4} \mathrm{Pt}_{2}$ : C, 36.74; $\mathrm{H}, 4.99$. Found: $\mathrm{C}, 36.89 ; \mathrm{H}, 4.62 .{ }^{1} \mathrm{H}$ NMR $\left(\mathrm{CDCl}_{3}, 400 \mathrm{MHz}\right): \delta=7.83(\mathrm{~d}, J$ $=8.82 \mathrm{~Hz}, 4 \mathrm{H} \mathrm{Ar}-\mathrm{H}), 7.34(\mathrm{~d}, J=8.31$ $\mathrm{Hz}, 4 \mathrm{H}, \mathrm{Ar}-\mathrm{H}), 2.21$ (m, 24H, $\left.-\mathrm{CH}_{2}-\right), 1.16$ $\left(\mathrm{m}, 36 \mathrm{H},-\mathrm{CH}_{3}\right) ;{ }^{13} \mathrm{C} \mathrm{NMR}\left(\mathrm{CDCl}_{3}, 100\right.$ $\mathrm{MHz}): \delta=194.55,136.12,131.39,130.30$, $130.12,101.53,100.21,17.12,8.73 ;{ }^{11} \mathrm{P}$ NMR $\left(\mathrm{CDCl}_{3}\right): \delta=8.22$. IR: $v=2105.68$ (alkyne $\mathrm{C} \equiv \mathrm{C}$ stretching), $1657.90 \quad(\mathrm{C}=\mathrm{O}$ stretching). ESI-MS: $\mathrm{m} / \mathrm{z}=1286$ ([bisPt-I $\left.+\mathrm{CH}_{3} \mathrm{CN}-\mathrm{I}^{-}\right]^{+}$).

\section{GeneralProcedure forthe Syntheses of the Macrocycles $M_{1}-M_{4}$}

$20 \mathrm{mg}(0.0145 \mathrm{mmol})$ of bisPt-I was dissolved in $6 \mathrm{~mL}$ of chloroform and stirred

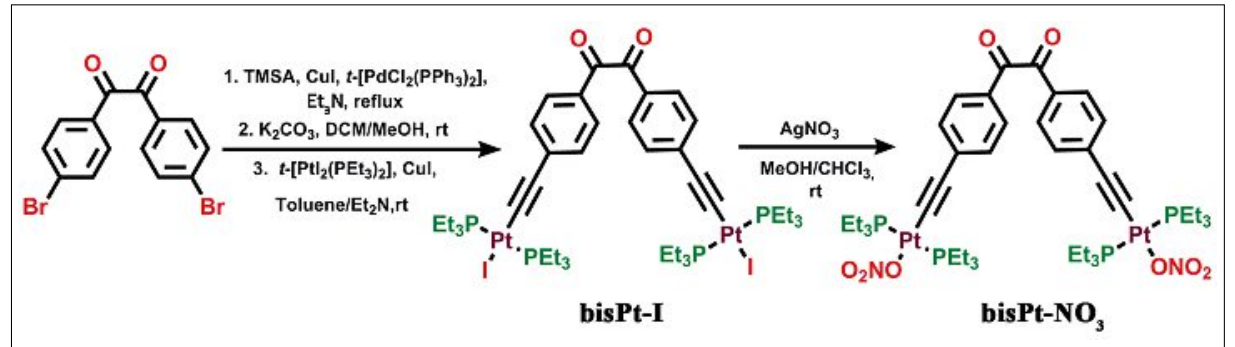

Scheme 2. Schematic representation of the synthesis of 4,4'-bis[trans-Pt( $\left.\mathrm{PEt}_{3}\right)_{2}\left(\mathrm{NO}_{3}\right)$ (ethynyl)]benzil (bisPt- $\mathrm{NO}_{3}$ ) from 4,4'-diethynylbenzil (1) and trans- $\mathrm{Ptl}_{2}\left(\mathrm{PEt}_{3}\right)_{2}$. with $1 \mathrm{~mL}$ methanolic solution of silver nitrate $(5.2 \mathrm{mg}, 0.030 \mathrm{mmol})$ for $2 \mathrm{~h}$ in dark at room temperature for in situ generation of the nitrate analogue bisPt-NO $\mathbf{N O}_{3}$. The resulting suspension was filtered through celite in order to remove the AgI precipitate. The solvent was evaporated completely and the residue was taken up in $6 \mathrm{~mL}$ of acetone, which was filtered through cotton and added to the chloroform solution of the corresponding donor (1.0 equiv.). The mixture was then heated at $60{ }^{\circ} \mathrm{C}$ for $12 \mathrm{~h}$. The final clear solution was dried completely under vacuum and the residue was washed with $4 \mathrm{~mL}$ chloroform and the products were obtained as yellow solid upon treating with cold diethyl ether.

Spectral data of bisPt-NO $:{ }^{1} \mathrm{H}$ NMR $\left(\mathrm{CDCl}_{3}, 400 \mathrm{MHz}\right): \delta=7.83(\mathrm{~d}, 4 \mathrm{H}, \mathrm{Ar}-\mathrm{H})$, 7.28 (d, 4H, Ar-H), 1.91 (m, 24H, $\left.-\mathrm{CH}_{2}-\right)$, $1.19\left(\mathrm{~m}, 36 \mathrm{H},-\mathrm{CH}_{3}\right) .{ }^{31} \mathrm{P}$ NMR $\left(\mathrm{CDCl}_{3}\right)$ : $\delta=20.21$.

\section{Synthesis of $M_{1}$}

Reaction of carbazole-based donor $\mathbf{L}_{1}$ (4.76 mg, $0.0145 \mathrm{mmol}$ ) with bisPt$\mathbf{N O}_{3}$ gave macrocycle $\mathbf{M}_{1}$ in an isolated yield of $86 \%$. Anal calcd for $\mathrm{C}_{124} \mathrm{H}_{170} \mathrm{~N}_{14} \mathrm{O}_{16} \mathrm{P}_{8} \mathrm{Pt}_{4}$ : C, 47.42; H, 5.46; N, 6.24. Found: C, 47.89; H, 5.32; N, 6.11. ${ }^{1} \mathrm{H} \mathrm{NMR}\left(\mathrm{CDCl}_{3}, 400 \mathrm{MHz}\right): \delta=9.25(\mathrm{~b}$, $4 \mathrm{H}), 9.01(\mathrm{~b}, 4 \mathrm{H}), 7.84(\mathrm{~m}, 12 \mathrm{H}), 7.60$ $(\mathrm{m}, 8 \mathrm{H}), 7.36(\mathrm{t}, 8 \mathrm{H}), 7.14(\mathrm{~s}, 4 \mathrm{H}), 4.46$ $(\mathrm{b}, 4 \mathrm{H}), 1.93(\mathrm{~m}, 48 \mathrm{H}), 1.42(\mathrm{~m}, 6 \mathrm{H})$, $1.16(\mathrm{~m}, 72 \mathrm{H}) .{ }^{31} \mathrm{P}$ NMR $\left(1: 1 \mathrm{MeCN}-\mathrm{d}_{3} /\right.$ $\left.\mathrm{CDCl}_{3}\right): \delta 16.33$. ESI-MS (m/z): 1508.48 $\left[\mathbf{M}_{1}-2 \mathrm{NO}_{3}^{-}\right]^{2+}, \quad 984.65\left[\mathbf{M}_{2}-3 \mathrm{NO}_{3}^{-}\right]^{3+}$, $722.98 \quad\left[\mathbf{M}_{3}-4 \mathrm{NO}_{3}^{-}\right]^{4+} ; \quad$ IR $\left(\mathrm{v} / \mathrm{cm}^{-1}\right)$ : 2964.87, 2111.75, 1661.58.

\section{Synthesis of $M_{2}$}

Reaction of donor $\mathbf{L}_{2}$ (3.45 mg, 0.0145 mmol) with bisPt-NO $\mathbf{N}_{3}$ according to the above-mentioned procedure gave macrocycle $\mathbf{M}_{2}$ in $91 \%$ yield. Anal calcd for $\mathrm{C}_{112} \mathrm{H}_{164} \mathrm{~N}_{12} \mathrm{O}_{16} \mathrm{P}_{8} \mathrm{Pt}_{4}: \mathrm{C}, 45.40 ; \mathrm{H}, 5.58 ; \mathrm{N}$, 5.67. Found: $\mathrm{C}, 44.89 ; \mathrm{H}, 5.30 ; \mathrm{N}, 5.33 .{ }^{1} \mathrm{H}$ NMR $\left(\mathrm{CDCl}_{3}, 400 \mathrm{MHz}\right): \delta=8.42(\mathrm{~d}, 4 \mathrm{H})$, $7.77(\mathrm{~m}, 8 \mathrm{H}), 7.35(\mathrm{~m}, 20 \mathrm{H}), 6.91(\mathrm{~s}, 4 \mathrm{H})$, $5.32(\mathrm{~s}, 8 \mathrm{H}), 1.70(\mathrm{~m}, 48 \mathrm{H}), 1.08(\mathrm{~m}, 72 \mathrm{H})$. ${ }^{31} \mathrm{P}$ NMR $\left(\mathrm{MeCN}-\mathrm{d}_{3} / \mathrm{CDCl}_{3}\right): \delta 16.23$. ESIMS (m/z): $1418.50\left[\mathbf{M}_{2}-2 \mathrm{NO}_{3}^{-}\right]^{2+}, 925.67$ $\left[\mathbf{M}_{2}-3 \mathrm{NO}_{3}^{-}\right]^{3+}, 678.75\left[\mathbf{M}_{2}-4 \mathrm{NO}_{3}^{-}\right]^{4+} ; \mathrm{IR}$ (v/cm $\left.{ }^{-1}\right): 2996.25,2114.13,1662.22$.

\section{Synthesis of $M_{3}$}

Macrocycle $\mathbf{M}_{3}$ was isolated in almost quantitative yield by the reaction of $\mathbf{L}_{3}(3.45$ $\mathrm{mg}, 0.0145 \mathrm{mmol}$ ) with bisPt-NO . Anal calcd for $\mathrm{C}_{112} \mathrm{H}_{164} \mathrm{~N}_{12} \mathrm{O}_{16} \mathrm{P}_{8} \mathrm{Pt}_{4}: \mathrm{C}, 45.40 ; \mathrm{H}$, $5.58 ; \mathrm{N}, 5.67$. Found: C, 45.50; H, 5.75; N, 5.42. ${ }^{1} \mathrm{H} \mathrm{NMR}\left(\mathrm{CDCl}_{3}, 400 \mathrm{MHz}\right): \delta=8.23$ (s, 4H), $7.85(\mathrm{~d}, 8 \mathrm{H}), 7.55(\mathrm{~d}, 4 \mathrm{H}), 7.42$ (d, 12H), 7.29 (d, 4H), $7.06(\mathrm{~s}, 4 \mathrm{H}), 5.28$ $(\mathrm{s}, 8 \mathrm{H}), 1.76(\mathrm{~m}, 48 \mathrm{H}), 1.10(\mathrm{~m}, 72 \mathrm{H}) .{ }^{31} \mathrm{P}$ NMR $\left(1: 1 \mathrm{MeCN}_{-} \mathrm{d}_{3} / \mathrm{CDCl}_{3}\right): \delta 16.52$. ESIMS (m/z): $1418.45^{3}\left[\mathrm{M}_{3}-2 \mathrm{NO}_{3}^{-}\right]^{2+}, 925.64$ 


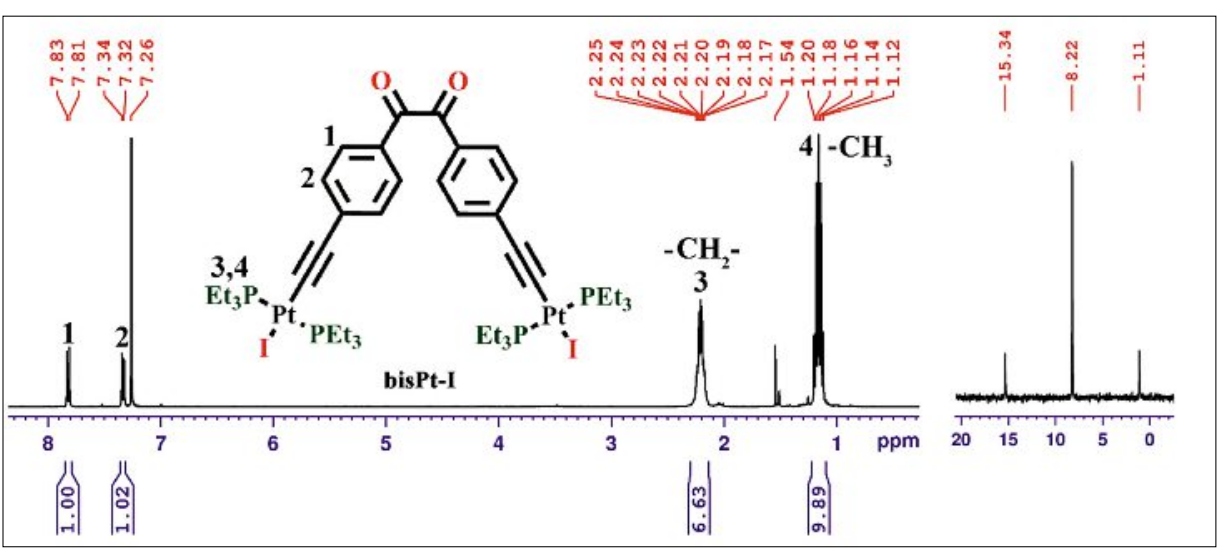

Fig. 1. ${ }^{1} \mathrm{H}$ (left) and ${ }^{13} \mathrm{P}$ (right) NMR spectra of bisPt-I recorded in $\mathrm{CDCl}_{3}$.

$\left[\mathrm{M}_{3}-3 \mathrm{NO}_{3}^{-}\right]^{3+}, 678.73\left[\mathrm{M}_{3}-4 \mathrm{NO}_{3}^{-}\right]^{4+}$. IR (v/cm $\left.{ }^{-1}\right): 2965.38,2114.79,1660.97$.

\section{Synthesis of $M_{4}$}

Macrocycle $\mathbf{M}_{4}$ was obtained by the reaction of donor $\mathbf{L}_{4}^{4}(4.9 \mathrm{mg}, 0.0145 \mathrm{mmol})$ with bisPt-NO $\mathrm{NO}_{3}$ in $77 \%$ isolated yield. Anal calcd for $\mathrm{C}_{128} \mathrm{H}_{172} \mathrm{~N}_{12} \mathrm{O}_{16} \mathrm{P}_{8} \mathrm{Pt}_{4}$ : C, 48.61; H, 5.48; N, 5.31. Found: C, 48.72; $\mathrm{H}, 5.23 ; \mathrm{N}, 5.08 .{ }^{1} \mathrm{H}$ NMR $\left(\mathrm{MeCN}_{3}, 400\right.$ $\mathrm{MHz}): \delta=8.47(\mathrm{~m}, 8 \mathrm{H}), 7.79(\mathrm{~b}, 20 \mathrm{H})$, $7.37(\mathrm{~m}, 8 \mathrm{H}), 7.18(\mathrm{~m}, 4 \mathrm{H}), 6.98(\mathrm{~m}$, 4H), 6.38 (b, 8H), $1.63(\mathrm{~m}, 48 \mathrm{H}), 0.97(\mathrm{~m}$, $72 \mathrm{H}) .{ }^{31} \mathrm{P}$ NMR $\left(\mathrm{MeCN}-\mathrm{d}_{3}\right): \delta 16.02$. ESI$\operatorname{MS}(\mathrm{m} / \mathrm{z}): 1519.62\left[\mathbf{M}_{4}-2 \mathrm{NO}_{3}^{-}\right]^{2+}, 992.15$ $\left[\mathbf{M}_{4}-3 \mathrm{NO}_{3}^{-}\right]^{3+}, 728.68\left[\mathbf{M}_{4}-4 \mathrm{NO}_{3}^{-}\right]^{4+}$. IR (v/cm $\left.{ }^{-1}\right): 2996.60,2113.69,2662.72$.

\section{X-ray Data Collection and Structure Refinements}

A suitable single crystal of the iodide analogue bisPt-I was mounted on a crystal mounting loop after coating with paratone oil and diffracted on a Bruker SMART APEX CCD diffractometer using graphite-monochromatic Mo-K $\alpha$ radiation $(0.7107 \AA)$ at $293 \mathrm{~K}$. The structure was solved by direct methods using SHELX-97 software incorporated with WINGX package. ${ }^{[9]}$ Empirical absorption corrections were applied with SADABS. All the non-hydrogen atoms were refined with anisotropic displacement coefficients while the hydrogen atoms were fixed to their geometric positions suggested by the program.

\section{Results and Discussion}

\section{Design, Synthesis and Characterisation of bis Pt-NO}

Design of a bisplatinum(II) acceptor compatible with various type of donors can be obtained by incorporating a 'not so rigid' backbone which will allow the acceptor to adjust its binding sites in accordance with the incoming donor coordination environment. However, the restricted flexibility will retain its characteristic structural coding as a building unit. After thorough survey of the literature, the benzil moiety has been judiciously selected for this purpose due to its unique structural features (long $\mathrm{C}-\mathrm{C}$ bond of $\sim 1.54 \AA$ and conformational flexibility) as earlier reported for some of its derivatives. ${ }^{[10]}$ The $\mathrm{C}=\mathrm{O}$ groups in the benzil moiety are found to reside in different planes as a consequence of the strong electronic repulsion between the oxygen atoms which make 'cis' conformation highly unfavourable. On the other hand, the strong electron withdrawing nature of the oxygen restricts the delocalization of electron density between two $\mathrm{C}=\mathrm{O}$ moieties effectively imposing 'only' single bond character to the carbonyl $\mathrm{C}-\mathrm{C}$ bond, resulting in a twisted geometry intermediate between cis and trans conformations of the benzil moiety.

To synthesize the desired bisplatinum acceptor bisPt-NO $\mathbf{N}_{3}, 4,4$ '-dibromobenzil was first converted to 4,4'-diethynylbenzil (1) by a Sonagashira coupling reaction with trimethylsilylacetylene followed by desilylation of the alkyne groups with potassium carbonate.

Subsequently, 4,4'-diethynylbenzil $\mathbf{1}$ was incorporated with two platinum centres by $\mathrm{Cu}(\mathrm{I})$-catalysed metal insertion reaction with trans $-\mathrm{PtI}_{2}\left(\mathrm{PEt}_{3}\right)_{2}$ to obtain the iodide analogue bisPt-I in 64\% yield (Scheme 2). bisPt-I was fully characterised by multi-
Table 1. Crystallographic data and structure refinement parameters for bisPt-I

$\begin{array}{lr}\text { empirical formula } & \mathrm{C}_{42} \mathrm{H}_{68} \mathrm{I}_{2} \mathrm{O}_{2} \mathrm{P}_{4} \mathrm{Pt}_{2} \\ \text { formula weight } & 1372.82 \\ \text { crystal system } & \text { Monoclinic } \\ \text { space group } & \mathrm{C} \\ T, \mathrm{~K} & 293(2) \\ \lambda(\mathrm{Mo} \mathrm{K} \alpha, \AA & 0.71073 \\ \mathrm{a}, \AA & 39.683(14) \\ b, \AA & 8.831(3) \\ c, \AA & 14.908(5) \\ \alpha, \text { deg } & 90.0 \\ \beta, \text { deg } & 95.770(10) \\ \gamma, \text { deg } & 90.0 \\ V, \AA^{3} & 5198(3) \\ Z & 4 \\ \rho_{\text {calcd }}, \mathrm{g} \mathrm{cm}^{-3} & 1.754 \\ \mu, \mathrm{mm}^{-1} & 6.717 \\ \mathrm{GOF}^{\mathrm{a}} & 1.226 \\ \mathrm{R}_{1}^{\mathrm{b}}[I>2 \sigma(I)] & 0.0380 \\ w R_{2}^{\mathrm{c}} & 0.1181\end{array}$

${ }^{\mathrm{a}} \mathrm{GOF}=\left\{\Sigma\left[w\left(F_{0}^{2}-F_{\mathrm{c}}^{2}\right)^{2}\right] /(n-p)\right\}^{1 / 2}$, where $n$ and $p$ denotes the number of data points and the number of parameters, respectively.

${ }^{\mathrm{b}} \mathrm{R}_{1}=\left(\Sigma\left|I F_{0}\right|-\mid F_{c} I I\right) / \Sigma\left|F_{0}\right|$;

${ }^{c} W R_{2}=\left\{\Sigma\left[W\left(F_{0}^{2}-F^{2}\right)^{2}\right] / \Sigma\left[w\left(F_{0}^{2}\right)^{2}\right]\right\}^{1 / 2}$, where $w$ $=1 /\left[\sigma^{2}\left(F_{0}^{2}\right)+(a P)^{2}+(b P)\right]$ and $P=\left[\max \left(0, F_{0}^{2}\right)\right.$ $\left.+2 F_{c}^{2}\right] / 3$.

nuclear $\left({ }^{1} \mathrm{H},{ }^{13} \mathrm{C},{ }^{31} \mathrm{P}\right)$ NMR spectroscopy, IR and ESI-MS spectrometry. The ${ }^{1} \mathrm{H}$ NMR spectrum consists of two doublets in the aromatic region $(\delta=7.83, J=8.3 \mathrm{~Hz}$ and $7.32 \mathrm{ppm}, J=8.3 \mathrm{~Hz}$ ) along with two multiplets in the upfield region $(\delta=2.25$, $J=3.8 \mathrm{~Hz}$ and $1.12, J=8.0 \mathrm{~Hz}$ ) showing 1:1:6:9 intensity ratios corresponding to the aromatic and ethyl protons, respectively. Moreover, a sharp singlet at $\delta=8.72$ ppm in ${ }^{31} \mathrm{P}\left\{{ }^{1} \mathrm{H}\right\}$ NMR spectra along with two concomitant ${ }^{195} \mathrm{Pt}$ satellite peaks $\left({ }^{1} J_{\mathrm{Pt}-\mathrm{P}}\right.$ $=1153.5 \mathrm{~Hz}$ ) confirmed its purity (Fig. 1). The strong peaks at $v=2105 \mathrm{~cm}^{-1}$ and $1657 \mathrm{~cm}^{-1}$ in the IR spectra were assigned to the ethynyl and carbonyl vibrations, respectively. Single crystal X-ray diffraction experiment unambiguously established the structure of bisPt-I (Fig. 2). The active ac-

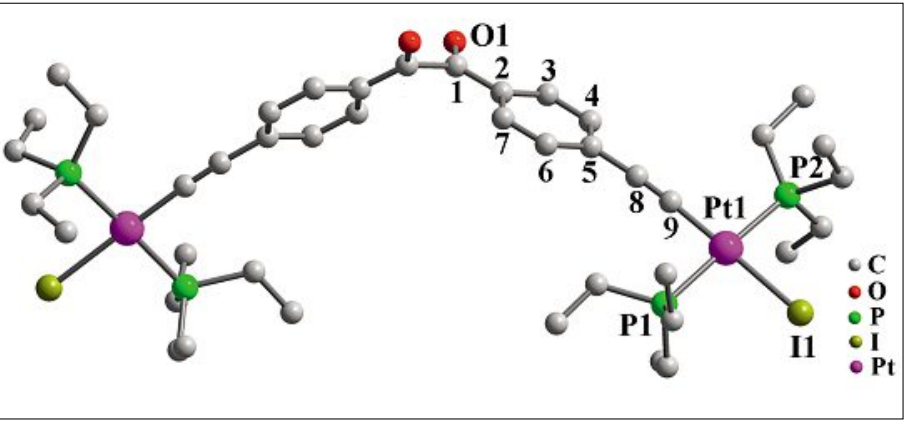

Fig. 2. Crystal structure of bisPt-I showing the twisted conformation in solid state. Hydrogen atoms are omitted for clarity. 
Table 2: Selected bond lengths and bond angles compared with benzil [10(a)] and the selected torsional angles in bisPt-I.

\begin{tabular}{|c|c|c|c|c|}
\hline & bisPt-I & Benzil & & bisPt-I \\
\hline $\mathrm{C}(1)-\mathrm{C}(1)$ & $1.535(16) \AA$ & $1.523(7) \AA$ & $\mathrm{O}(1)-\mathrm{C}(1)-\mathrm{C}(1)-\mathrm{O}(1)$ & $-113.50(3)^{\circ}$ \\
\hline $\mathrm{C}(1)-\mathrm{O}(1)$ & $1.230(9) \AA$ & $1.210(7) \AA$ & $\mathrm{C}(2)-\mathrm{C}(1)-\mathrm{C}(1)-\mathrm{C}(2)$ & $-118.69(2)^{\circ}$ \\
\hline $\mathrm{C}(1)-\mathrm{C}(2)$ & $1.461(10) \AA$ & $1.482(7) \AA$ & $\mathrm{O}(1)-\mathrm{C}(1)-\mathrm{C}(2)-\mathrm{C}(7)$ & $178.24(2)^{\circ}$ \\
\hline $\mathrm{O}(1)-\mathrm{C}(1)-\mathrm{C}(1)$ & $116.7(7)^{\circ}$ & $118.1(4)^{\circ}$ & $\mathrm{O}(1)-\mathrm{C}(1)-\mathrm{C}(2)-\mathrm{C}(3)$ & $-4.03(4)^{\circ}$ \\
\hline $\mathrm{C}(2)-\mathrm{C}(1)-\mathrm{C}(1)$ & $118.9(8)^{\circ}$ & $119.3(4)^{\circ}$ & $\mathrm{C}(4)-\mathrm{C}(5)-\mathrm{Pt}(1)-\mathrm{P}(2)$ & $35.96(2)^{\circ}$ \\
\hline $\mathrm{O}(1)-\mathrm{C}(1)-\mathrm{C}(2)$ & $124.3(7)^{\circ}$ & $122.4(4)^{\circ}$ & $\mathrm{C}(6)-\mathrm{C}(5)-\mathrm{Pt}(1)-\mathrm{P}(1)$ & $34.43(2)^{\circ}$ \\
\hline $\mathrm{C}(7)-\mathrm{C}(2)-\mathrm{C}(1)$ & $123.4(7)^{\circ}$ & $119.4(4)^{\circ}$ & & \\
\hline $\mathrm{C}(3)-\mathrm{C}(2)-\mathrm{C}(1)$ & $119.1(6)^{\circ}$ & $118.9(4)^{\circ}$ & & \\
\hline
\end{tabular}

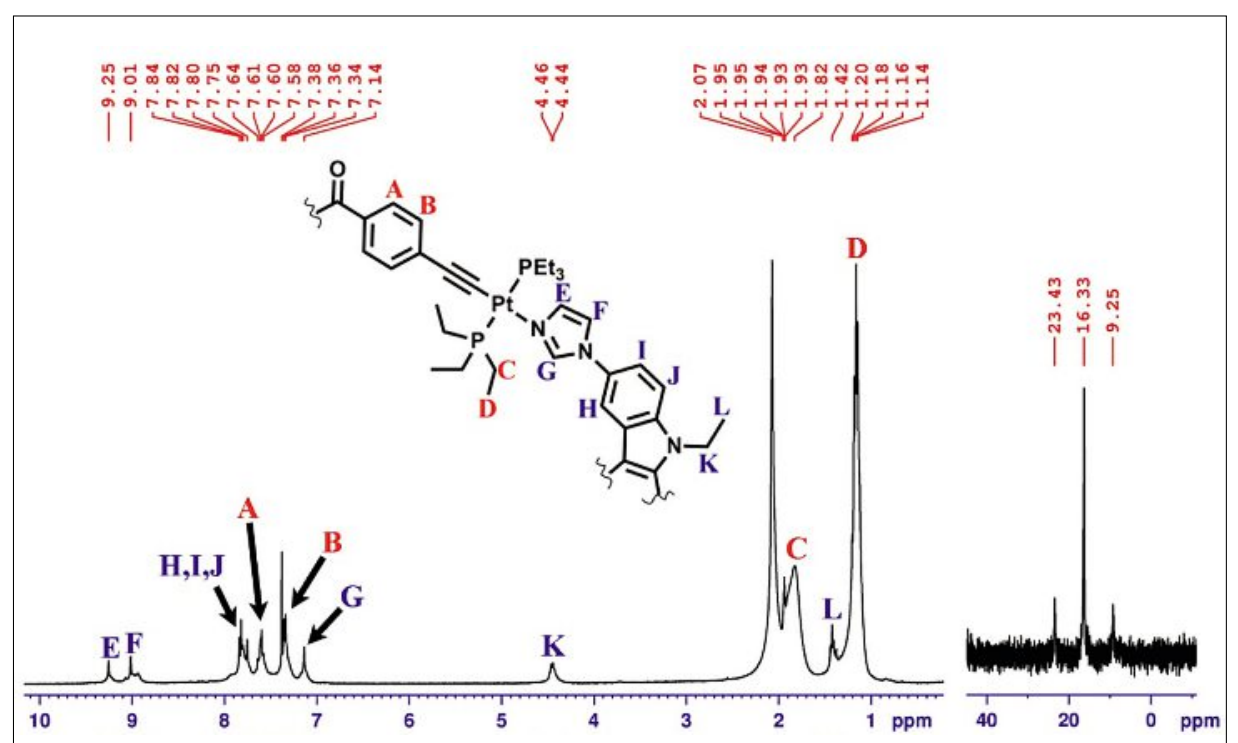

Fig. 3. ${ }^{1} \mathrm{H}$ (left) and ${ }^{31} \mathrm{P}$ (right) NMR spectra of $\mathbf{M}_{1}$ in $\mathrm{CDCl}_{3}-\mathrm{CD}_{3} \mathrm{CN}$.

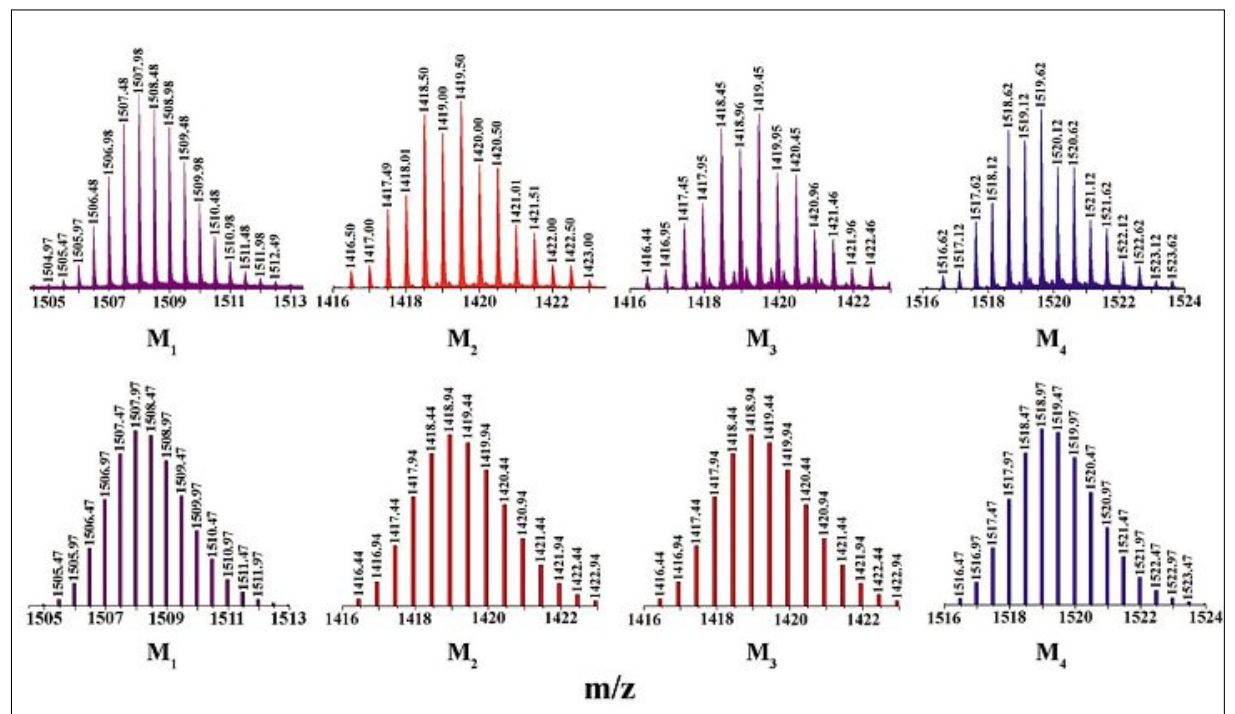

Fig. 4. Experimental (above) and theoretical (below) isotopic distribution pattern of $\mathbf{M}_{1}-\mathbf{M}_{4}$ for the $2+$ charged species. ceptor bisPt-NO $\mathbf{N}_{3}$ was synthesized by treating bisPt-I with 2.1 equiv. silver nitrate in a chloroform-methanol mixture, which was also characterized by multinuclear NMR spectroscopy (Supplementary Data, Fig. S9, S10). Interestingly, exchange of iodine caused a shift in the peak position from $\delta=8.72 \mathrm{ppm}$ to $\delta=20.21 \mathrm{ppm}$ in the ${ }^{31} \mathrm{P}$ NMR spectrum.

The diffraction quality single crystals were obtained by the slow evaporation of dichloromethane-hexane solution of bisPt-I at room temperature. bisPt-I crystallised in monoclinic crystal system in the $\mathrm{C} 2 / \mathrm{c}$ space group (Table 1 ). The solid-state structure shows that the two $\mathrm{C}=\mathrm{O}$ groups of the benzil moiety are not exactly trans-oriented, instead twisted along the $\mathrm{C}-\mathrm{C}$ bond possessing a torsional angle of $-113.50(3)^{\circ}\left(\Phi_{\text {O-C-C-O }}\right)$. Moreover, the C-C bond distance is 1.535(16) $\AA$ and hence suggesting single bond character (Table 2). The two platinum centres are 16.240(89) $\AA$ apart from each other describing a $\sim 122^{\circ}$ bite angle with respect to the centroids of the carbonyl carbon atoms making it a unique building block. The phosphorous atoms of the trans-blocking $\mathrm{PEt}_{3}$ groups are situated outside the benzoyl plane at an angle of around $35^{\circ}$.

\section{Synthesis and Characterisation of [2 + 2] Self-assembled Metallamacrocycles $\left(M_{1}-M_{4}\right)$}

In order to check the versatility of the acceptor bisPt-NO $\mathrm{NO}_{3}$ to become amenable for a range of donor systems, four imidazole-based ditopic donors $\left(\mathbf{L}_{\mathbf{1}}-\mathbf{L}_{\mathbf{4}}\right)$ with different shapes, sizes and flexibility were selected to self-assemble their corresponding $[2+2]$ metallamacrocycles. While $\mathbf{L}_{1}$ being a carbazole-based rigid donor possessing an almost $90^{\circ}$ donor angle, the $\mathbf{L}_{2}-$ $\mathbf{L}_{4}$ donors are rather flexible in their coordination directionality. $\mathbf{L}_{2}$ and $\mathbf{L}_{3}$ are structural isomers possessing different donor environments, while $\mathbf{L}_{\mathbf{4}}$ is functionalised with a fluorescent anthracene backbone.

In a general synthetic methodology, the iodide analogue bisPt-I was converted in situ to its nitrate analogue bisPt-NO $\mathbf{N O}_{3}$ and then treated separately with an equivalent amount of the donors $\mathbf{L}_{\mathbf{1}}-\mathbf{L}_{\mathbf{4}}$ by heating overnight in chloroform-acetone solvent mixture to obtain self-assembled macrocycles $\mathbf{M}_{\mathbf{1}}-\mathbf{M}_{\mathbf{4}}$ (Scheme 1). The sharp single peak, along with two satellite peaks, in the ${ }^{31} \mathrm{P}\left\{{ }^{1} \mathrm{H}\right\}$ NMR spectra appeared in the shielded region compared to the acceptor bisPt-NO $\mathrm{N}_{3}$ due to the enhanced platinum to phosphorous back donation upon ligand coordination demonstrating the formation of a single product in each case (Figs 3 and S12-S19, Supplementary Data).

Diffusion ordered spectroscopy (DOSY) of $\mathbf{M}_{4}$ showed single diffusion coefficient for all the peaks and further 
confirmed its purity (Fig. S20). The stoichiometry of the building blocks in $\mathbf{M}_{-}-$ $\mathbf{M}_{4}$ were determined from the ESI-MS spectra where in each case the isotopic distribution patterns of the peaks matched with their respective theoretical patterns corresponding to the expected [2+2] assemblies (Figs 4 and S22-S25). ESI-MS spectra of $\mathbf{M}_{1}$ showed three sharp peaks at $\mathrm{m} / \mathrm{z}=1508.48$, 984.65 and 722.98 (Fig. S22) corresponding to $\left[\mathbf{M}_{1}-2 \mathrm{NO}_{3}\right]^{2+}$, $\left[\mathbf{M}_{1}-3 \mathrm{NO}_{3}^{-}\right]^{3+}$ and $\left[\mathbf{M}_{1}-4 \mathrm{NO}_{3}^{-}\right]^{4+}$ fragments, respectively. Similarly for $\mathbf{M}_{2}$ and $\mathbf{M}_{3}$ (having identical molecular formulae), ESI-MS peaks were obtained at $\mathrm{m} / \mathrm{z}$ $=1418.50\left(\mathbf{M}_{2}\right)$ and $1418.45\left(\mathbf{M}_{3}\right)$ (theoretical value $=1418.45), 925.67\left(\mathbf{M}_{2}\right)$ and 925.64 $\left(\mathbf{M}_{3}\right)$ (theoretical value $\left.=925.64\right)$, $678.75\left(\mathbf{M}_{2}\right)$ and $678.73\left(\mathbf{M}_{3}\right)$ (theoretical value $=678.73)$ corresponding to the $\left[\mathbf{M}_{2} / \mathbf{M}_{3}-2 \mathrm{NO}_{3}^{-}\right]^{2+}, \quad\left[\mathbf{M}_{2} / \mathbf{M}_{3}-3 \mathrm{NO}_{3}^{-}\right]^{3+}$ and $\left[\mathbf{M}_{2} / \mathbf{M}_{3}-4 \mathrm{NO}_{3}\right]^{4+}$ fragments, respectively (Supplementary Data, Figs S23, S24). All the four macrocycles absorbed at $353 \mathrm{~nm}$ owing to the $\pi-\pi^{*}$ transition of the ethynyl conjugated backbone of the acceptor (Fig. S29). $\mathbf{M}_{4}$ shows strong fluorescence due to the presence of anthracene moiety with characteristic triple humped curve in the emission spectra (Fig. S30).

In order to investigate their structural nature, semi-empirical geometry optimizations using PM6 method were carried out which show $\mathbf{M}_{1}$ forming a beautiful flat ring-shaped architecture where the furthest stretch is about $3.90 \mathrm{~nm}$ between the ethyl groups (Fig. 5) and also having inner diameters of $2.43 \mathrm{~nm}$ and $1.58 \mathrm{~nm}$ respectively. The $\mathbf{M}_{2}, \mathbf{M}_{3}$ and $\mathbf{M}_{4}$ have similar kind of architectures where aromatic backbones

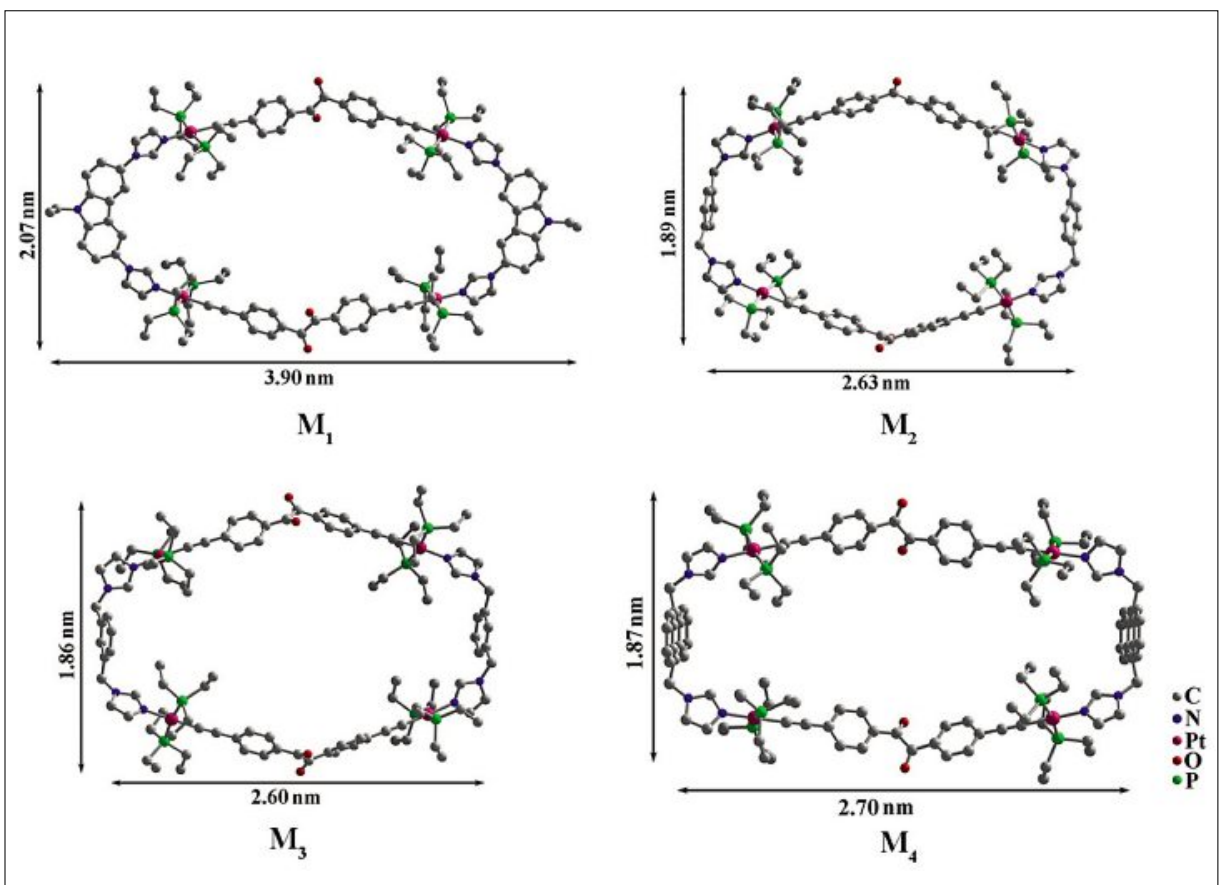

Fig. 5. Geometry optimized structures (PM6) of the macrocycles $\mathbf{M}_{1}, \mathbf{M}_{2}, \mathbf{M}_{3}$ and $\mathbf{M}_{4}$ Hydrogen atoms have been omitted for clarity. of the donors are oriented perpendicular to the longer diagonal axis (Figs 5, S31S34). Interestingly, $\mathbf{M}_{4}$ has little bending near the acceptor sites shaping the molecule in a boat-like geometry (Fig. S34). In all the cases triethylphosphine groups were oriented outwards from the ring to release steric strain. The torsional angles associated with the acceptor (both $\Phi_{\mathrm{C} 2-\mathrm{C} 1-\mathrm{C} 1-\mathrm{C} 2}$ and $\Phi_{\text {O1-C1-C1-O1 }}$ ) significantly vary in four structures over a range from $132.6^{\circ}$ to $140.7^{\circ}$ for $\Phi_{\mathrm{C} 2-\mathrm{Cl}-\mathrm{Cl}-\mathrm{C} 2}$ and from $133.2^{\circ}$ to $139.4^{\circ}$ for $\Phi_{\mathrm{Ol}-\mathrm{Cl}-\mathrm{Cl}-\mathrm{Cl} 2}$ which reflects the flexible donor binding capability of the acceptor

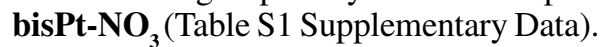

\section{Conclusions}

In conclusion, we have synthesized a new benzil-based semi-rigid $\mathrm{Pt}^{\mathrm{II}}{ }_{2}$ organometallic acceptor bisPt-I and its nitrate analogue bisPt-NO in high yields. Multinuclear NMR, and X-ray diffraction analysis of bisPt-I, unequivocally confirmed their formation. The benzil functionality was chosen due to its long carbonyl $\mathrm{C}-\mathrm{C}$ bond and to investigate the effect of semi-rigidness on controlling the shape and size of final supramolecular architectures. The presence of unsaturated ethynyl functionality imparts further stability to keep the final molecular architectures intact under various experimental conditions. The stoichiometry (1:1) combination of bisPt-NO $\mathrm{N}_{3}$ with a series of ditopic imidazole donors $\left(\mathbf{L}_{\mathbf{1}}-\mathbf{L}_{\mathbf{4}}\right)$ resulted in the formation of [2+2] self-assembled metallacycles $\mathbf{M}_{\mathbf{1}}-\mathbf{M}_{\mathbf{4}}$ in quantitative yields. The purity and selective formation of $[2+2]$ [ metallacycles in each case was verified by various spectroscopic techniques and structural information of these assemblies was obtained through geometry optimisation with the PM6 semi-empirical method. To the best of our knowledge, these metallamacrocycles are the first examples of discrete supramolecular architectures obtained from benzil-based semi-rigid organometallic acceptor via metal-ligand coordination. Our group is now actively working to design various types of flexible/semi-rigid organometallic Pt(II) acceptors to generate a library of unprecedented functional metallamacrocycles.

\section{Supplementary Data}

Supplementary Data containing NMR, ESI MS, and electronic spectra and optimized coordinates is provided. CCDC 966747 contains the supplementary crystallographic data for this paper. These data can be obtained free of charge from The Cambridge Crystallographic Data Centre via www.ccdc.cam.ac.uk/data_request/cif.

\section{Acknowledgements}

B. R. is grateful to IISc Bangalore for a research fellowship. P.S.M thanks the Department of Science and Technology (DST), India, for financial support in the form of a Swarnajayanti fellowship.

Received: July 7, 2015

[1] a) J.-M. Lehn, Proc. Natl. Acad. Sci. USA 2002, 99, 4763; b) J. W. Steed, J. L. Atwood, 'Supramolecular Chemistry', John Wiley \& Sons Ltd, UK, 2009; c) Q. Gan, T. K. Ronson, D. A. Vosburg, J. D. Thoburn, J. R. Nitschke, J. Am. Chem. Soc. 2015, 137, 1770; d) C. J. Bruns, D. Fujita, M. Hoshino, S. Sato, J. F. Stoddart, M. Fujita, J. Am. Chem. Soc. 2014, 136, 12027.

[2] a) M. Fujita, Chem. Soc. Rev. 1998, 2, 417; b) B. H. Northrop, H.-B. Yang, P. J. Stang, Chem. Commun. 2008, 5896; c) U. N. Nehete, G. Anantharaman, V. Chandrasekhar, R. Murugavel, H. W. Roesky, D. Vidovic, J. Magull, K. Samwer, B. J. Sass, Angew. Chem., Int. Ed. 2004, 43, 3832; d) N. L. Toh, N. Nagarithinum, J. J. Vittal, Angew. Chem., Int. Ed. 2005, 44, 2237; e) A. M. Spokoyny, M. S. Rosen, P. A. Ulmann, C. Stern, C. A. Mirkin, Inorg. Chem. 2010, 49, 1577; f) K. Acharyya, P. S. Mukherjee, Chem.-Eur. J. 2015, 21, 1; g) M. Yoshizawa, M. Tamura, M. Fujita, Science 2006, 312, 251; h) L. Xu, Y.-X. Wang, L.-J. Chen, H.-B. Yang, Chem. Soc. Rev. 2015, 44, 2148; i) L. Chen, P. S. Reiss, S. Y. Chong, D. Holden, K. E. Jelfs, T. Hasell, M. A. Little, A. Kewley, M. E. Briggs, A. Stephenson, K. M. Thomas, J. A. Armstrong, J. Bell, J. Busto, R. Noel, J. Liu, D. M. Strachan, P. K. Thallapally, A. I. Cooper, Nat. Mater. 2014, 13, 954; j) I. V. Grishagin, J. B. Pollock, S. Kushal, T. R. Cook, P. J. Stang, B. Z. Olenyuk, Proc. Nat. Acad. Sci. USA 2014, 111, 18448.

[3] a) S. Hiraoka, Y. Yamauchi, R. Arakane, M. Shionoya, J. Am. Chem. Soc. 2009, 131, 11646; b) M. Jurícek, J. C. Barnes, N. L. Strutt, N. A. Vermeulen, K. C. Ghooray, E. J. Dale, P. R. McGonigal, A. K. Blackburn, A.-J. Avestro, J. F. Stoddart, Chem. Sci. 2014, 5, 2724; c) E. J. Dale, N. A. Vermeulen, A. A. Thomas, J. C. Barnes, M. Jurícek, A. K. Blackburn, 
N. L. Strutt, A. A. Sarjeant, C. L. Stern, S. E. Denmark, J. F. Stoddart, J. Am. Chem. Soc. 2014, 136, 10669; d) C. Zhang, C.-F. Chen, J. Org. Chem. 2007, 72, 9339.

[4] a) S. Li, J. Huang, F. Zhou, T. R. Cook, X. Yan, Y. Ye, B. Zhu, B. Zheng, P. J. Stang, J. Am. Chem. Soc. 2014, 136, 5908; b) B. Sun, M. Wang, Z. Lou, M. Huang, C. Xu, X. Li, L.-J. Chen, Y. Yu, G. L. Davis, B. Xu, H.-B. Yang, X. Li, J. Am. Chem. Soc. 2015, 137, 1556; c) K. Harris, Q.F. Sun, S. Sato, M. Fujita, J. Am. Chem. Soc. 2013, 135, 1249; d) S. Chakraborty, S. Mondal, S. Bhowmick, J. Ma, H. Tan, S. Neogic, N. Das, Dalton Trans. 2014, 43, 13270; e) D. Samanta, P. S. Mukherjee, Chem. Commun. 2014, 50, 1595; f) D. Samanta, P. S. Mukherjee, Chem.Eur. J. 2014, 20, 5649 .

[5] R. Chakrabarty, P. S. Mukherjee, P. J. Stang, Chem. Rev. 2011, 111, 6810.

[6] a) D. K. Chand, K. Biradha, M. Fujita, S. Sakamoto, K. Yamaguchi, Chem. Commun. 2002, 2486; b) S. Ghosh, P. S. Mukherjee, $J$ Org. Chem. 2006, 71, 8412; c) S. Ø. Scott, E. L. Gavey, S. J. Lind, K. C. Gordona, J. D. Crowley,
Dalton Trans. 2011, 40, 12117; d) T. H. Noh, E. Heo, K. H. Park, O.-S. Jung, J. Am. Chem. Soc. 2011, 133, 1236; e) P. J. Steel, Acc. Chem. Res. 2005, 38, 24; f) A. K. Bar, R. Chakrabarty, P. S. Mukherjee, Inorg. Chem. 2009, 48, 10880; g) C. M. Hartshorn, P. J. Steel, Chem. Commun. 1997, 541; h) X.-J. Li, F.-L. Jiang, M.-Y. Wu, S.-Q. Zhang, Y.-F. Zhou, M.-C. Hong, Inorg. Chem. 2012, 51, 4116.

[7] a) S. Ghosh, P. S. Mukherjee, Organometallics 2008, 27, 316; b) S. Shanmugaraju, A. K. Bar, K.-W. Chi, P. S. Mukherjee, Organometallics 2010, 29, 2971; c) A. K. Bar, S.Shanmugaraju, K.-W. Chi, P. S. Mukherjee, Dalton Trans. 2011, 40, 2257; d) B. Gole, S. Shanmugaraju, A. K. Bar, P. S. Mukherjee, Chem. Commun. 2011, 47, 10046; e) S. Shanmugaraju, D. Samanta, B. Gole, P. S. Mukherjee, Dalton Trans. 2011, 40, 12333; f) S. Shanmugaraju, V. Vajpayee, K.-W. Chi, P. J. Stang, P. S. Mukherjee, Inorg. Chem. 2012, 51, 4817; g) B. Roy, A. K. Bar, B. Gole, P. S. Mukherjee, J. Org. Chem. 2013, 78, 1306; h) S. Shanmugaraju, P. S. Mukherjee, Chem.-Eur. J. 2015, 21, 6656 .
[8] a) H.-P. Zhou, P. Wang, Z.-J. Hu, L. Li, J.-J. Chen, Y. Cui, Y.-P Tian, J.-Y. Wu, J.-X. Yang, X.-T. Tao, M.-H. Jiang, Eur. J. Inorg. Chem. 2007, 13, 1854; b) M. Yang, K. Stappert, A.-V. Mudring, J. Mat. Chem. C 2014, 2, 458; c) L. Yang, L. Luo, S. Zhang, X. Su, J. Lan, C.-T. Chen, J. You, Chem. Commun. 2010, 46, 3938; d) W.-Q. Kan, J. Yang, Y.-Y. Liu, J.-F. Ma, Polyhedron 2011, 30, 2106.

[9] a) G. M. Sheldrick, Acta Crystallogr 2008, A64, 112; b) L. J. Farrugia, J. Appl. Cryst. 2012, 45, 849.

[10] a) C. J. Brown, R. Sadanaga, Acta Cryst. 1965, 18,158 ; b) E. J. Gabe, Y. L. Page, F. L. Lee, Acta Cryst. 1981, B37, 197; c) Q. Shen, K. Hagen, J. Phys. Chem. 1987, 91, 1357. 